\title{
Relasi Orang tua-Anak Pada Keluarga Melayu (Analisis Berdasarkan Perspektif Psikologi Indijinus)
}

\author{
Sri Wahyuni, Raudatussalamah
}

\author{
Fakultas Psikologi Universitas Islam Negeri Sultan Syarif kasim Riau \\ email: sri.wahyuni@uin-suska.ac.id
}

\section{Artikel INFO}

Diterima: 10 Okt 2020

Direvisi :25 Nov 2020

Disetujui: 2 Des 2020

DOI:

http://dx.doi.org/10.24014/ jp.v14i2.10962

\section{Abstrak}

Relasi orang tua-anak pada keluarga Melayu unik karena adanya tanggung jawab masing-masing antara orang tua dan anak. Pemahaman akan adanya tanggung jawab masing-masing ini menjadikan relasi terkadang bermasalah. Tujuan penelitian ini untuk mengukur relasi orang tua-anak pada keluarga Melayu. Metode penelitian ini mengadopsi metode kualitatif dengan pendekatan psikologi indijinus. Responden dalam penelitian ini adalah anak Melayu yang sudah memasuki remaja usia 12-20 tahun dengan jumlah 340 orang. Pengujian ini dilakukan berdasarkan analisis tematik menggunakan empat indikator kewajiban orang tua terhadap anak, yaitu hutang bela dengan pelihara, hutang tunjuk dengan ajar, hutang tuang dengan isi dan hutang bekal dengan pakaian. Dan berdasarkan tiga indikator kewajiban anak terhadap orang tua yaitu sifat tahu membayar utang, sifat tahu diri, dan sifat nan bersifat. Hasil penelitian diperoleh bahwa jumlah responden yang sangat dekat dengan ibu lebih banyak dibanding ayah. Cara ayah dalam berelasi dengan anak cenderung dengan mengajarkan kebaikan (hutang tunjuk dengan ajar) dan dengan ibu yaitu merawat dan mengasuh agar anak sehat jasmani dan rohani (hutang bela dengan pelihara). Sedangkan dari sisi anak, anak melakukan relasi dengan ayah dengan cara berbakti dan ibu dengan cara berprestasi, dimana keduanya termasuk indikator tahu membayar hutang. Penelitian ini memberikan manfaat bagi orang tua dan anak dari keluarga dengan budaya Melayu dalam memahami model relasi antara orang tua dan anak, dan pengembangan ilmu psikologi dalam hal relasi orang tua-anak pada keluarga dengan budaya Melayu. Pada peneliti selanjutnya, disarankan untuk mengembangkan alat ukur relasi orang tua-anak pada keluarga Melayu.

Keyword: parent-child relation, Malay family

\section{The Indigenous Psychology of Parents-Children Relationship In Malay Families}

\begin{abstract}
The parents-children relationship of Malay families are unique due to their responsibilities. The way of understanding them sometimes makes problematic relationship. The purpose of this study is to measure the relationship of parentschildren in Malay families. This research method is a qualitative method with the psychological approach. The respondents of this study are Malay children in 12-20 years about 340 people. This test based on analysis thematic uses four indicators of parents obligation to children, such as protection, goodness, teaching, provider. Moreover, based on three indicators of children obligation to parents such as return the kindness, know to respect and respectful character. The findings were the number of respondents who are very close to mother more than dad. Great relationships of father and children tend to reach by goodness and the mother is caring for and nurturing that children physically and mentally healthy. Whereas in terms of children, children make relations with fathers through filial methods and mothers with achievements, both of which are indicators of return the kindness. This study provides benefits for parents and children from families with the Malay culture in understanding the kind of relationships between parents and children, and the development of the science of psychology in terms of parentschildren relationships in families with Malay culture. For the next research, it is expected to develop a measurement tool for parents-children of Malay families.
\end{abstract}

Keywords: parents-children relation, Malay family 


\section{Pendahuluan}

Kualitas relasi antara orang tua dan anak sangat penting bagi kehidupan anak. Orang tua bertanggung jawab untuk membesarkan anak sesuai dengan nilai-nilai agama dan budaya yang dianut oleh keluarga dan masyarakat dimana keluarga tersebut tinggal. Orang tua membimbing anak untuk menemukan dan mengamalkan keyakinan, sikap, dan perilaku yang akan menyertai anak sepanjang hidupnya karena keluarga adalah agen sosialisasi anak yang pertama yang mempersiapkannya untuk menghadapi kehidupan sosial, akademis, profesional, moral, dan ekonomi. Oleh karena itu, perkembangan anak sangat dipengaruhi oleh relasi orang tua dan anak.

Lebih lanjut, relasi orang tua-anak dimulai sejak bayi, bahkan sejak dalam kandungan. Relasi orang tua-anak semenjak bayi akan mempengaruhi perkembangan anak, baik perkembangan fisik, kognitif, emosi maupun sosial. Piaget mengungkapkan bahwa anak belajar dari proses interaksi dengan orang tua dan proses eksplorasi lingkungan (Mukhlis, Hirmaningsih, Asra, Lestari, Yulianti, \& Wahyuni, 2014). Begitu pula dengan Erikson, relasi orang tua-anak ketika bayi akan menciptakan rasa percaya anak terhadap orang tua dan ini menjadi awal terbentuknya kelekatan anak dengan orang tua (Santrock, 2002). Relasi orang tua-anak ini terjadi secara timbal balik dan saling mempengaruhi kedua belah pihak (Aoki, 2003).

Kualitas relasi orang tua-anak sangat berpengaruh terhadap perkembangan anak. Relasi orang tua dan anak yang bekualitas akan meningkatkan kesejahteraan psikologis anak hingga anak menjadi dewasa (Amato, 1994; Aoki, 2003). Sementara itu, anak yang memiliki relasi yang kurang berkualitas dengan orang tua cenderung mengalami kesepian dibandingkan dengan anak yang memiliki relasi yang berkualitas dengan orang tua (Xu, 2017). Seorang ibu yang ingin memiliki relasi yang sehat dengan anaknya perlu memiliki sikap percaya diri, rasa hormat, peka terhadap permasalahan anak, mampu berkolaborasi dengan anak, berbagi perasaan dan pandangan-pandangan anak serta mau menerimanya. Anak-anak yang tumbuh dengan relasi ibu-anak yang sehat ini akan menjadi individu mandiri dengan harga diri yang tinggi (Sahin, 2014). Relasi yang erat antara ibu dan anak ini sangat penting guna meningkatkan penyesuaian diri anak, khususnya pada lingkungan yang baru (Hough, Templin, Kulwicki, Ramaswamy, \& Katz, 2009), dan menurunkan kecenderungan anak memiliki masalah-masalah perilaku, baik masalah perilaku eksternal (perilaku agresif dan kenakalan) maupun internal (kecemasan dan depresi) (Aroian, Templin, Hough, Ramaswamy \& Katz, 2011). Tidak hanya kualitas relasi antara ibu dan anak, relasi yang akrab dengan ayah juga ditemukan meningkatkan kebahagiaan, kepuasan, dan mengurangi rasa tertekan atau stres hingga anak menjadi dewasa (Amato, 1994). Jadi, relasi orang tua anak sangat besar pengaruhnya terhadap tumbuh kembang anak hingga dewasa.

Pada perkembangan zaman saat ini terdapat peralihan bentuk relasi orang tuaanak. Relasi yang berkualitas bukan berarti orang tua selalu bersama dengan anak, namun lebih mengarah kepada penggunaan waktu yang berkualitas antara anak dengan orang tua (Collishaw, Gardner, Maughan, Scott \& Pickles, 2011). Anak laki-laki yang sudah remaja memiliki bentuk relasi yang berbeda dengan anak perempuan terhadap orang tua mereka. Anak perempuan lebih dekat terhadap ibunya, membutuhkan kontroling yang tinggi dari ibu, sering mengkomunikasikan aktivitas di luar rumah dengan ibu dan suka menghabiskan waktu bersama dengan ibunya. Sedangkan anak laki-laki cenderung lebih dekat dengan ayahnya dan lebih banyak menghabiskan waktu yang berkualitas dengan ayah. 
Penggunaan waktu yang berkualitas dengan anak ini mampu mencegah terjadinya perilaku anti sosial pada anak yang sudah remaja (Collishaw, Gardner, Maughan, Scott \& Pickles, 2011)

Relasi orang tua-anak dalam ilmu psikologi juga dilihat dari gaya pengasuhan orang tua. Orang tua yang mengasuh dengan penuh kasih sayang, hangat dan memberikan dukungan pada anak akan berpengaruh terhadap kesejahteraan psikologis anak yang terlihat dari kebahagiaan dan kepuasan ketika masa anak-anak hingga dewasa, sebaliknya orang tua yang sangat mengontrol anak dengan kaku cenderung menjadikan anaknya kurang bahagia bahkan hingga dewasa (Stafford, Kuha, Galeb, Mishrad \& Richards, 2016).

Salah satu faktor yang mempengaruhi relasi orang tua-anak adalah budaya. Bronfenbrenner mengungkapkan bahwa faktor nilai-nilai dan budaya sangat mempengaruhi perkembangan anak karena bagaimana anak berinteraksi dengan orang tua dan orang-orang di sekitarnya tidak dapat lepas dari nilai-nilai moral, etika budaya yang berlaku di mana anak hidup (Papalia, 2010). Selanjutnya budaya akan membentuk identitas etnis individu, misalnya identitas seorang muslim adalah menggunakan jilbab bagi perempuan dan segala aturan dalam berinteraksi sosial (Britto, 2008). Pada budaya Barat yang cenderung individualis, gaya pengasuhan otoriter dipandang negatif dan memiliki dampak yang buruk bagi anak. Namun pada budaya kolektif masyarakat Timur khususnya masyarakat dengan budaya Melayu, gaya pengasuhan otoriter tidak dipandang negatif karena dianggap bersifat normatif dalam mengasuh dan mengoptimalkan tumbuh kembang anak (Keshavarz \& Baharudin, 2009).

Di provinsi Riau yang sebagian besar masyarakatnya muslim dan memiliki budaya Melayu. Pada masyarakat Melayu, anak memiliki nilai yang sangat tinggi, sebagaimana pepatah melayu "tuah ayam pada kakinya, tuah manusia pada anaknya". Pada masyarakat Melayu, relasi orang tuaanak sangat erat, masing-masing orang tua memiliki peran utama yang berbeda. Ibu memiliki hak yang istimewa terhadap anaknya karena anak masuk dalam suku ibunya dan ibu memiliki kewajiban yang utama dalam mendidik anak dibandingkan ayah, ayah memiliki kewajiban utama untuk mencari nafkah (Nisdawati, 2016). Tapi, pada penelitian yang dilakukan oleh Juhari, Yaacob \& Talib (2013) menemukan bahwa ayah tidak hanya mencari nafkah, tetapi juga mengajarkan nilai-nilai moral, tata cara berdoa, membaca Al-Quran, dan mengajak anak untuk berpuasa bersama. Hal ini merupakan wujud tanggungjawab ayah terhadap Allah SWT guna mencapai tujuan hidup di dunia dan akhirat.

Relasi orang tua-anak pada masyarakat Melayu terlihat dari pelaksanaan hak dan kewajiban baik oleh orang tua maupun anak. Pada masyarakat Melayu ada empat macam kewajiban orang tua kepada anak yang menjadi hutang bagi orang tua dan wajib untuk ditunaikan serta menjadi hak bagi anak, yakni pertama, "hutang bela dengan pelihara" yaitu kewajiban orang tua untuk menyempurnakan perawatan dan pengasuhan terhadap anak supaya kuat dan sehat baik jasmani maupun rohani. Kedua, "hutang tunjuk dengan ajar" yaitu kewajiban dan tanggung jawab orang tua untuk menyempurnakan pendidikan dan pengajaran dengan berbagai ilmu pengetahuan yang bermanfaat supaya anak menjadi manusia yang cerdas dan berpengetahuan luas. Ketiga, "hutang tuang dengan isi", yakni kewajiban dan tanggung jawab orang tua kepada anak untuk menyempurnakan, mengisi, dan menuangkan nilai-nilai luhur yang bersumber dari ajaran agama, adat istiadat, serta norma sosial lainnya yang ada di dalam masyarakat. Orang tua mengharapkan anak 
dapat menerapkan nilai-nilai luhur dalam kehidupannya, misalnya tidak sombong walaupun telah memiliki banyak ilmu. Keempat, "hutang bekal dengan pakaian" yaitu kewajiban dan tanggung jawab orang tua agar mempersiapkan, menyediakan dan menyempurnakan seluruh keperluan hidup anak, baik lahir maupun batin (Efendi, 2011).

Pada masyarakat dengan budaya Melayu, tidak hanya membahas tentang kewajiban orang tua terhadap anak, namun juga kewajiban anak terhadap orang tua yang menjadi hak bagi orang tua, yaitu pertama, "sifat tahu membayar utang", artinya anak Melayu harus tahu membalas budi, terutama kepada orang tua, kerabat, dan masyarakat. Dalam ungkapan Melayu disebutkan: "tahu kan pahit ibu mengandung, tahu kan pahit ayah menjaga, tahu kan sakit membesarkannya, tahu kan utang yang dibebannya. Tahu kan belas kasihan orang, tahu kan bela pelihara orang, tahu kan budi baik orang". Kedua, "sifat tahu diri", artinya, anak Melayu harus menjaga diri dalam pergaulan sehari-hari di dalam keluarga dan masyarakat. Ketiga,"sifat nan bersifat", artinya anak Melayu harus menghargai dan menghormati orang lain, serta meletakkan sesuatu pada tempatnya(Aryanti, 2015). Kewajiban kewajiban tersebut seharusnya masih dilaksanakan dengan baik oleh remaja Melayu. Tujuan penelitian ini untuk mengkaji secara mendalam bagaimana relasi orang tua-anak pada masyarakat dengan budaya Melayu di Provinsi Riau.

\section{Metode}

\section{Partisipan}

Responden dalam penelitian ini adalah anak Melayu yang sudah memasuki usia remaja dan tinggal di Pekanbaru, Riau. Usianya sekitar 12 - 20 tahun dengan jumlah 340 orang remaja Melayu Riau (133 laki-laki, dan 207 perempuan).

\section{Pengukuran}

Penelitian ini menggunakan pendekatan psikologi indijinus, dengan menggunakan open-ended questioner. Adapun pertanyaan tertutupnya adalah "seberapa dekat kamu dengan ayahmu?" dan "seberapa dekat kamu dengan ibumu?". Selanjutnya pertanyaan terbuka pada penelitian ini adalah "Bagaimana ayah dalam merawat dan mengasuhmu? bagaimana ibu dalam merawat dan mengasuhmu?

Analsis data

Langkah selanjutnya adalah dengan melakukan koding dan Analisis Data. Proses koding dilakukan kepada semua jawaban responden (multiple respon). Kemudian jawaban responden dikelompokkan ke dalam kategori-kategori kecil berdasarkan kata kunci dalam jawaban responden. Kategorikategori kecil ini dikelompokkan berdasarkan tema yang sama. Selanjutnya kategorikategori kecil ini disusun menjadi beberapa tema besar, diutamakan menggunakan teori yang telah ada dan jika tema tidak dapat dikelompokkan ke dalam teori yang telah ada maka hal ini dianggap suatu temuan baru. Pengkodean dan pengkategorisasian menggunakan program software N-Vivo 8 (QSR. International, 2012). Selanjutnya dilakukan beberapa analisis statistik antara lain, tabulasi silang (cross tabulation), uji beda dengan t-test dan one-way ANOVA.

\section{Hasil}

Hasil analisis yang diperoleh dari jawaban jawaban subjek penelitian terkait pertanyaan pertanyaan dari kuesioner yang diberikan dapat dijabarkan sebagai berikut:

1) Pertanyaan penelitian terkait seberapa dekat remaja dengan ayah?

Dari pertanyaan tersebut diperoleh jawaban sebagai berikut: 
Tabel 1 Aitem 1 (seberapa dekat dengan Ayah)

\begin{tabular}{|c|c|c|}
\hline \multicolumn{2}{|c|}{ Frequency } & Percent \\
\hline Tidak Dekat & 7 & 2,1 \\
\hline Kurang dekat & 8 & 2,4 \\
\hline Agak Dekat & 34 & 10,0 \\
\hline Dekat & 117 & 34,4 \\
\hline Sangat Dekat & 174 & 51,2 \\
\hline Total & 340 & 100,0 \\
\hline $\begin{array}{l}\text { Berdasarkan tabel } 1 \text { di atas, dari } 340 \\
\text { remaja, } 174 \text { remaja memiliki hubungan } \\
\text { yang sangat dekat dengan ayah. }\end{array}$ & 2) & $\begin{array}{l}\text { Seberapa dekat remaja dengan ibu? } \\
\text { Selanjutnya untuk pertanyaan } \\
\text { seberapa dekat dengan ibu diperoleh } \\
\text { jawaban sebagi berikut: }\end{array}$ \\
\hline
\end{tabular}

Tabel 2 Aitem 2 (Seberapa dekat dengan Ibu)

\begin{tabular}{lcc}
\hline & Frequency & Percent \\
\hline Tidak Dekat & 1 & 0,3 \\
Kurang Dekat & 0 & 0 \\
Agak Dekat & 8 & 2,4 \\
Dekat & 36 & 10,6 \\
Sangat Dekat & 295 & 86,8 \\
\hline Total & 340 & 100,0 \\
\hline
\end{tabular}

Berdasarkan table 2 di atas dapat dijelaskan bahwa sebanyak $295(86,8 \%)$ remaja sangat dekat dengan ibu .

3) Bagaimana cara ayah mengasuh Cara pengasuhan ayah yang ditemukan dalam penelitian dikelompokkan dalam berbagai katagori. Kategori tersebut meliputi, menafkahi, memberikan perhatian, mengajarkan kebaikan, mendidik atau mengasuh dalam hal agama. Masing masing ketegori ini kemudian disesuaikan dengan konsep penga-suhan dalam budaya melayu. Maka dikelompokkan kategori tersebut sebagai berikut:

a) Mengasuh dengan memberi nafkah (menafkahi remaja sandang, pangan dan papan) merupakan konsep hutang bekal dengan pakaian. b) Mengasuh dengan memberikan perhatian (lemah lembut, kasih sayang, perhatian) merupakan konsep hutang bela dengan pelihara

c) Mengasuh dengan mengajarkan kebaikan (mengajarkan berbuat baik (kebaikan), mengingatkan untuk berbuat baik, menasehati) merupakan konsep hutang tunjuk dengan ajar.

d) Mengasuh dalam hal agama atau mendidik dalam hal agama (mengajari anak ilmu agama, mengajar mengaji) merupakan konsep hutang tuang dengan isi.

Adapun rekapan hasil tersebut dapat dilihat pada tabel 4 di bawah ini: 
Tabel 3 Aitem 3 (Bagaimana cara Ayah mengasuh)

\begin{tabular}{lcc}
\hline & Frequency & Percent \\
\hline Hutang Bekal dengan Pakaian & 44 & 12,9 \\
Hutang Bela dengan Pelihara & 95 & 27,9 \\
Hutang Tuang dengan Isi & 17 & 5,0 \\
Hutang tunjuk dengan Ajar & 184 & 54,1 \\
\hline Total & 340 & 100,0 \\
\hline
\end{tabular}

Berdasarkan tabel di atas diperoleh hasil bahwa cara pengasuhan ayah yang paling tinggi adalah hutang tunjuk dengan ajar (mengajarkan kebaikan) $54,1 \%$.

4) Bagaimana cara ibu mengasuh?

Sedangkan untukjawaban bagaimana cara ibu mengasuh diperoleh hasil sebagai berikut:

a. mengasuh dengan memberi nafkah (menyiapkan sarapan, makanan dan pakaian, merawat dan membesarkan) merupakan konsep hutang bekal dengan pakaian.

b. Mengasuh dengan memberikan perhatian (lemah lembut, kasih sayang, perhatian) merupakan konsep hutang bela dengan pelihara

c. Mengasuh dengan mengajarkan kebaikan (mengajarkan kemandirian, mengingatkan untuk berbuat baik, disiplin, memperhatikan urusan sekolah) merupakan konsep hutang tunjuk dengan ajar.

d. Mengasuh dalam hal agama atau mendidik dalam hal agama (beribadah kepada Allah, memperhatikan pergaulan, mendidik supaya menjadi anak yang sholeh/sholehah) merupakan konsep hutang tuang dengan isi.

Adapun Rekapan pengasuhan ibu dapat dilihat dalam tabel berikut ini:

Tabel 4 Aitem 4 (Bagaimana cara Ibu mengasuh)

\begin{tabular}{lcc}
\hline & Frequency & Percent \\
\hline Hutang Bekal dengan Pakaian & 41 & 12,1 \\
Hutang Bela dengan Pelihara & 131 & 38,5 \\
Hutang Tuang dengan isi & 52 & 15,3 \\
Hutang tunjuk dengan ajar & 116 & 34,1 \\
\hline Total & 340 & 100 \\
\hline
\end{tabular}

Berdasarkan tabel di atas diperoleh hasil bahwa cara pengasuhan ibu yang paling tinggi adalah hutang bela dengan pelihara (memberikan perhatian) sebesar 38, $5 \%$.

Hasil penelitian terkait pertanyaan cara pengasuhan ayah dan ibu memiliki kategori yang sama. Namun demikian terdapat perbedaan dalam hal prioritas terkait pengasuhan, pada ayah yang paling utama adalah hutang tunjuk dengan ajar (mengajarkan kebaikan), sedangkan ibu hutang bela dengan pelihara (memberikan perhatian). Begitu pula dalam hal hutang tuang dengan isi (mengajarkan nilai agama), lebih tinggi ibu dibanding ayah.

5) Apa yang dilakukan sebagai anak terhadap Ayah? 
Cara anak berlaku kepada orang tuanya khususnya kepada ayah dalam penelitian ini berupa berbakti, menghormati. Hal tersebut dapat dikategorikan sebagai berikut:

a. Berbakti (berbakti, patuh, taat, membahagiakan, berprestasi) termasuk dalam sifat tahu membayar hutang. b. Menghormati (sikap hormat, sopan santun) termasuk dalam sifat nan bersifat.

c. Others.

Adapun persentase dan kategorisasi dapat dilihat pada tabel 6 berikut:

Tabel 5 Aitem 11 (Apa yang kamu lakukan sebagai anak kepada Ayah)

\begin{tabular}{lcc}
\hline & Frequency & Percent \\
Others & 5 & 1,5 \\
\hline sifat nan bersifat & 45 & 13,2 \\
tahu membayar hutang (berbakti) & 189 & 55,6 \\
tahu membayar hutang (berprestasi) & 89 & 26,2 \\
tahu membayar hutang & 12 & 3,5 \\
(membahagiakan) & 340 & 100,0 \\
\hline Total & & \\
\hline
\end{tabular}

Berdasarkan tabel 5 di atas, sebanyak $189(55,6 \%)$ orang remaja menjawab dengan cara berbakti (patuh, taat), sedangkan 89 $(26,2 \%)$ menjawab dengan cara berprestasi, selanjutnya 12 (3,5\%) remaja dengan cara membahagiakan ayah. Berbakti, berprestasi dan membahagiakan merupakan tugas anak kepada orang tua yang termasuk dalam sifat tahu membayar hutang.

6) Apa yang dilakukan sebagai anak terhadap Ibu?

Cara anak berlaku kepada kepada ibu dalam penelitian ini berupa berbakti, menghormati. Kedua cara ini dapat dikategorikan sebagai berikut:

a. Berbakti (berbakti, patuh, taat, membahagiakan, berprestasi dengan cara mendoakan ibu) termasuk dalam sifat tahu membayar hutang.

b. Menghormati (sikap hormat, sopan santun) termasuk dalam sifat nan bersifat.

c. Others.

Adapun persentase dan kategorisasi dapat dilihat pada tabel 7 berikut:

Tabel 6 Aitem 12 (Apa yang kamu lakukan sebagai anak kepada Ibu)

\begin{tabular}{lcccc}
\hline & Frequency & Percent & $\begin{array}{c}\text { Valid } \\
\text { Percent }\end{array}$ & $\begin{array}{c}\text { Cumulative } \\
\text { Percent }\end{array}$ \\
\hline Others & 7 & 2,1 & 2,1 & 2,1 \\
sifat nan bersifat( menghormati) & 43 & 12,6 & 12,6 & 14,7 \\
tahu membayar hutang (berbakti) & 187 & 55,0 & 55,0 & 69,7 \\
tahu membayar hutang (berprestasi) & 50 & 14,7 & 14,7 & 84,4 \\
tahu membayar hutang (membahagiakan) & 53 & 15,6 & 15,6 & 100,0 \\
\hline Total & 340 & 100,0 & 100,0 & \\
\hline
\end{tabular}


Berdasarkan tabel 6 di atas, sebanyak $187(55, \%)$ orang remaja menjawab dengan cara berbakti (patuh, taat), sedangkan $53(15,6 \%)$ menjawab dengan cara membahagiakan ibu, selanjutnya $50(14,7 \%)$ remaja dengan cara berprestasi,. Selain itu cara yang dilakukan adalah dengan menghormati (sopan santun, sikap hormat), sebanyak $43(12,6 \%)$ remaja memberikan jawaban tersebut. Kategori ini merupakan tugas anak yang termasuk dalam sifat yang bersifat.

Berdasarkan pertanyaan apa yang dilakukan anak terhadap ibu maupun ayah, diperoleh jawaban yang sama yaitu berbakti, yangtermasuk dalam sifat tahu membayar hutang.

\section{Pembahasan}

Hasil penelitian menemukan bahwa sebagian besar anak memiliki hubungan yang sangat dekat dengan orang tuanya, baik dengan ayah maupun ibu. Hasil ini menunjukkan bahwa budaya melayu memiliki relasi yang kuat dalam keluarga. Kedekatan antara orang tua dan anak merupakan hal yang penting dalam pengasuhan, karena hubungan yang baik dan berkualitas akan mempengaruhi penyesuaian anak dan kesejahteraan anak. Sebagaimana penelitian Amato (1994) dan Aoki (2003) yang menenmukan bahwa relasi orang tua dan anak yang bekualitas akan meningkatkan kesejahteraan psikologis anak hingga anak menjadi dewasa (Amato, 1994; Aoki, 2003).

Penerapan pengasuhan baik pada ayah maupun ibu memiliki persamaan aspek, hanya berbeda dalam dominansi. Hasil penelitian menemukan beberapa penerapan pengasuhan yang dilakukan oleh orang tua terhadap anak pada budaya melayu yang meliputi hutang bela dengan pelihara, hutang tunjuk dengan ajar, hutang tuang dengan isi, dan hutang bekal dengan pakaian.
Hasil penelitian menemukan hutang bela dengan pelihara lebih didominasi oleh ibu. Hutang bela dengan pelihara" yaitu kewajiban orang tua untuk menyempurnakan pemeliharaan terhadap anak supaya kuat dan sehat baik jasmani maupun rohani. Untuk mencapai tujuan ini, orang tua melayu berpedoman kepada pepatah "disempurnakan bungkus dengan isinya, diselimuti dengan kasih sayang. Sebagaimana subjek menyatakan bahwa "ibu mengasuh dengan baik, sabar dan penuh kasih sayang. Ibu mengingatkan kami kalau salah, tapi dengan cara yang halus/lembut. Ayah mengasuh dengan sabar, apapun akan dilakukan ayah untukku dan adek-adek".

Hutang Bela dengan pelihara memiliki persamaan pandangan dengan dimensi penerimaan dalam teori pengasuhan Baumrind yaitu berkenaan dengan sikap orang tua yang menerima, penuh kasih sayang, memahami, mau mendengarkan, dan berorientasi pada kebutuhan anak. Pada keluarga yang orang tuanya menerima dan tanggap dengan anak-anak, sering terjadi diskusi terbuka dan sering terjadi proses memberi dan menerima, seperti saling mengekspresikan kasih sayang dan simpati (Santrock, 2003). Sejalan dengan penjelasan dari Baumrind, propethic parenting dalam konteks pengasuhan dari sudut pandang Islam, tidak berbeda dengan budaya melayu, seperti mendidik dengan kasih sayang, lemah lembut, kesabaran (Suwaid, 2010). Tidak ada perbedaan pengasuhan antara terkait sikap orang tua terhadap anak baik dari teori barat maupun dalam pandangan budaya melayu dan pengasuhan dalam Islam. Pengasuhan baik dalam perspektif barat, Islam maupun budaya melayu memperhatikan aspek kasih sayang, sikap lemah lembut dalam pengasuhan. Anak anak berhak mendapatkan kasih sayang, kelembutan dan keceriaan (Al'Ik, 2017). 
Selanjutnya, hutang tunjuk dengan ajar dalam penelitian ini lebih didominasi oleh ayah. "Hutang tunjuk dengan ajar" yaitu kewajiban dan tanggung jawab orang tua untuk menyempurnakan pendidikan dan pengajaran dengan berbagai ilmu pengetahuan yang bermanfaat supaya anak menjadi manusia yang cerdas dan berpengetahuan luas, sebagaimana ungkapan melayu "barang kerja takkan sempurna, bila tidak menaruh ilmu". Hutang tunjuk dengan ajar diimplementasikan oleh orang tua dengan cara mengajarkan kebaikan, mengajak berbuat baik, mengingatkan untuk berbuat baik, dan menasehati. Sebagaimana yang disebutkan oleh subjek bahwa "ayah selalu mengajarkan saya bersikap baik kepada orang lain dan membantu orang lain dalam kesusahan. Ibu selalu mengingatkan saya agar bersikap sopan santun kepada orang lain". Hal ini menegaskan bahwa ilmu yang diajarkan orang tua kepada anak dalam bentuk nasehat, anjuran. Sebagaimana diungkapkan dalam pepatah melayu seperti, diajarkan segala yang patut, ditunjukan segala yang benar, kalau duduk suruh berguru, kalau tegak suruh bertanya.

Hutang tunjuk dengan ajar juga memiliki persamaan dengan teori yang dikembang oleh Baumrind (1991) yaitu dimensi kontrol pada aspek tuntutan (demandigness) meskipun dalam aspek ini lebih kepada harapan harapan orang tua seperti, mengharapkan dan berusaha agar anak dapat memenuhi standar tingkah laku, sikap serta tanggung jawab sosial yang tinggi atau yang telah ditetapkan. Sedangkan dalam dalam pandangan budaya melayu lebih kepada perlakuan orang tua. Namun pengasuhan merupakan kunci untuk mencapai harapan-harapan tersebut. Orang tua memiliki tanggung jawab untuk mendidik anak sejak mulai dari kandungan. Setelah lahir kewajiban orang untuk mendidik anak tentang tanggung jawab sosial kemsyarakatan, dalam hal ini pembentukan akhlak islami pada anak yang berorientasi pada adab (Suwaid, 2010; Al-'Ik, 2017).

"Hutang tuang dengan isi", yakni kewajiban dan tanggung jawab orang tua kepada anak untuk menyempurnakan, mengisi, dan menuangkan nilai-nilai luhur yang bersumber dari ajaran agama, adat istiadat, serta norma sosial lainnya yang ada di dalam masyarakat. Orang tua mengharapkan anak dapat menerapkan nilai-nilai luhur dalam kehidupannya, misalnya tidak sombong walaupun sudah memiliki banyak ilmu, sebagaimana pepatah melayu "kemumu di semak jatuh melayang seloranya, meski ilmu setinggi tegak tidak sembahyang apa gunanya”. Hutang tuang dengan isi merupakan bentuk pengasuhan yang dikembangkan oleh orang tua yang berorientasi pada agama atau mendidik dalam hal agama seperti, mengajari anak ilmu agama, dan mengajar mengaji. Sebagaimana pepatah melayu menyebutkan "hati dipahat dengan iman, dada dituang dengan lembaga, diisi lurus dengan benar, dituang berani dengan setia, ditegakkan tiang budinya, dikokohkan tiang amalnya, dikuatkan tiang amanahnya, didirikan tiang malunya". Dalam hal ini anak diajarkan untuk memiliki rasa malu, memiliki iman dengan cara pengasuhan yang mengajarkan nilai agama dan mengaji. Sebagaimana yang disebutkan oleh subjek bahwa "selama ayah mengasuh saya banyak mendapatkan ilmu agama sekalian adab dan tata tertib yang seharusnya anak lakukan kepada orrang tua". Sedangkan ibu, "bila saya tidak solat ibu saya mengingatkan supaya solat dengan hati lembut dan saya pun solat"

Pengasuhan yang menerapkan hutang tuang dengan isi apabila dilihat dari aspek kontrol dalam dimensi tuntutan memiliki persamaan dengan hutang tunjuk dengan ajar. Sedangkan dalam pandangan islam, 
pengasuhan yang menerapkan hutang tuang dengan isi merupakan kunci utama dalam mengasuh anak. Peran orang tua mengajarkan nilai nilai agama kepada anak, mengajak anak mendirikan sholat dan kewajiban dalam agama (Suwaid, 2010; Al-'Ik, 2017). Kewajiban orang tua dalam islam memiliki makna yang sama dengan pandangan budaya melayu terkait hutang tuang dengan isi.

"Hutang bekal dengan pakaian" yaitu kewajiban dan tanggung jawab orang tua agar mempersiapkan, menyediakan dan menyempurnakan seluruh keperluan hidup anak, baik lahir maupun batin. Mengasuh dengan memberi nafkah seperti menafkahi remaja dengan sandang, pangan dan papan. Sebagaimana subjek menjelaskan bahwa "ayah mencari nafkah untuk menyekolahkan saya dan memenuhi kebutuhan saya. Sedangkan ibu memberiku ASI pada waktu bayi”. Hutang bekal dengan pakaian merupakan kewajiban bagi orang tua. Apabila dilihat berdasarkan pengasuhan kenabian (prophetic parenting), ditemukan bahwa memberi nafkah merupakan bagian dari pengasuhan yang memang dianjurkan dalam Islam. Kewajiban mencari nafkah baik berupa sandang pangan dan papan merupakan hal yang harus ditunaikan oleh orang tua dalam budaya melayu maupun islam. Dalam pandangan Islam, menerima nafkah dari orang tua merupakan hak bagi anak (Suwaid, 2010; Rabi' 2016; 'Al-lk, 2017). Namun dalam teori Baumrind (1991) mencari nafkah merupakan pemenuhan kebutuhan yang termasuk dalam dimensi penerimaan.

Menurut Baumrind pengasuhan pada prinsipnya merupakan parental control, Baumrind (1991) mendefenisikan pola asuh sebagai pola sikap atau perlakuan orang tua terhadap remaja yang masing-masing mempunyai pengaruh tersendiri terhadap perilaku remaja antara lain terhadap kompetensi emosional, sosial, dan intelektual remaja. Hal ini sesuai dengan pandangan Islam, perilaku atau kesholehan orang tua mempengaruhi pribadi atau perilaku anak (Rabi', 2016). Sejalan dengan hal tersebut, hasil penelitian terkait relasi anak terhadap orang yang menjelaskan bentuk perilaku anak terhadap orang tua diperoleh hasil yaitu, sifat tahu membayar hutang dan sifat nan bersifat.

Sifat tahu membayar hutang merupakan sifat yang harus dimiliki oleh anak yang menunjukkan bakti anak kepada orang tua. Bakti anak kepada orang tua dalam penelitian ini diperoleh jawaban berbakti, patuh, taat, membahagiakan orang tua, berprestasi, dan mendoakan yang baik untuk orang tua. Seperti diketahui, nilai-nilai dalam budaya melayu identik dengan Islam. Dalam Islam, berbakti kepada orang tua merupakan hal yang utama dan diwajibkan bahkan tidak boleh ditinggalkan meskipun kedua orang tua sudah meninggal dunia.

Sifat nan bersifat merupakan sifat yang harus ditunjukkan oleh anak baik kepada orang tua, maupun kepada orang lain, yaitu berupa sifat menghormati. Termasuk sifat menghormati dalam penelitian ini seperti sikap hormat, dan sopan santun. Hal ini menunjukkan bahwa persoalan adab merupakan hal yang penting dalam budaya melayu. Sehingga anak harus memiliki sifat nan bersifat. Sifat ini tentu saja diperoleh dari pengajaran atau pendidikan orang tua. Pengajaran dan pendidikan yang diterapkan oleh orang tua akan membentuk akhlak yang sesuai dengan budaya melayu yang senantiasa seiring dengan ajaran Islam.

Semua aspek budaya dan norma sosial masyarakat Melayu wajib merujuk kepada ajaran Islam dan dilarang bertikai apalagi menyalahinya. Acuan ini menyebabkan Islam tidak dapat dipisahkan dari adat maupun norma-norma sosial lainnya dalam kehidupan masyarakat Melayu. 


\section{Kesimpulan}

Penelitian ini telah menjawab pertanyaan penelitian tentang relasi orang tua-anak pada budaya Melayu. Relasi orang tua-anak yang dilihat dari pengasuhan meliputi "hutang tunjuk dengan ajar, hutang tuang dengan isi, hutang bekal dengan pakaian dan hutang bela dengan pelihara". Dan perilaku anak terhadap orang tua yang meliputi "sifat nan bersifat, tahu membayar hutang (berbakti), tahu membayar hutang (berprestasi) dan tahu membayar hutang (membahagiakan)".

\section{Daftar Pustaka}

'Al-lk, Syekh Khalid bin Abdurrahman. (2017). Prophetic Parenting (Terj). Yogyakarta: Laksana

Amato, P. R. (1994). Father-child relations, mother-child relations, and offspring psychological well-being in early adulthood. Journal of Marriage and Family, 56 (4), 1031-1042.

Aoki, K. (2003). Psychology of ParentChild Relationship. Japan Medical Association Journal 46(2): 75-79.

Aroian, K. J., Templin, T. N., Hough, E. E., Ramaswamy, V, \& Katz, A. (2011). A Longitudinal Family-Level Model of Arab Muslim Adolescent Behavior Problems. Journal of Youth Adolescence, 40, 996-1011.

Aryanti, C. E. (2015). Sifat Nan Delapan Belas Ajaran Budi Pekerti Anak Melayu. Warta Sejarah. http://wartasejarah. blogspot.co.id/2015/06/sifat-nandelapan-belas-ajaran-budi.html.

Bireda, A. D. (2013). Parent-adolescent relationship and Adolescents' adjustment problems: adolescents' voices. Dissertation, online publication. South Africa: University Of South Africa.
Britto, P. R. (2008). Who Am I? Ethnic Identity Formation of Arab Muslim Children in Contemporary U.S. Society. J. Am. Acad. Child Adolesc. Psychiatry, 47 (8), 853-857.

Collishaw, S., Gardner, F., Maughan, B., Scott, J. \& Pickles, A. (2011). Do Historical Changes in Parent-Child Relationships Explain Increases in Youth Conduct Problems?. Journal of Abnormal Child Psychology, 1-14.

Efendi, Y. (2011). Budi Pekerti Melayu: Orang tua terhadap Anak. Dunia Melayu SeDunia. MelayuOnline.com.

Fuligni, A. J. \& Eccles, J.S. (1993). Perceived parent-child relationships and early adolescents' orientation toward peers. Developmental Psychology, 29 (4), 622-632.

Hough, H, s., Templin, T. N., Kulwicki, A., Ramaswamy, V. \& Katz, A (2009). "A model of mother-child Adjustment in Arab Muslim Immigrants to the US. Soc Sci Med. 69(9): 1377-1386.

Juhari, R., Yaacob, S. N., Talib, M. A. (2013). Father Involvement Among Malay Muslims in Malaysia. Journal of Family Issues, 34(2), 210-229.

Keshavarz, S \& Baharudin, R. (2009). Parenting Style in a Collectivist Culture of Malaysia. European Journal of Social Sciences, 10 (1), 66-73.

Kim, U., Yang, K-S., \& Hwang, K-K. (2010). Indigenous and Cultural Psychology, Memahami Orang dalam Konteksnya. Yogyakarta: Pustaka Pelajar.

Mukhlis, Hirmaningsih, Asra, Y. K., Lestari, Y. L., Yulianti, A., \& Wahyuni, S. (2014). Konsep \& Teori Perkembangan. Pekanbaru: Al- Mujtahadah.

Nisdawati. (2016). Nilai-nilai Tradisi Dalam Koba Panglimo Awang Masyarakat Melayu Pasir Pengaraian. Yogyakarta: Deepublish. 
Papalia, D. E., Old, S. W., \&Feldman, R. D. (2010). Human Development: Psikologi Perkembangan. Edisi Kesembilan. Jakarta: Kencana Prenada Media Group.

QSR. International. (2012). The N-Vivo Workbook. QSR. International. Pty. Ltd.

Rabi', Abu Al-Hamd. (2016). Membumikan Harapan (Terj). Solo: Era Adicitra Intermedia.

Sahin, F, T. (2014). Mother-Child Relation And Factors Affecting This Relation. International Journal of Science Culture and Sport, 2 (3), 79-88.

Santrock, J.W. (2002). Life Span Development, Perkembangan Masa Hidup. Jilid 1. Jakarta: Erlangga

Stafford, M., Kuha, D. L., Galeb, C. R., Mishrad, G., \& Richards, M. (2016). Parent-child relationships and offspring's positive mental wellbeing from adolescence to early older age. The Journal of Positive Psychology, 11, (3), 326-337.

Suwaid, M. N. Abdul Hafizh. (2010). Prophetic Parenting: Cara Nabi mendidik Anak. Yogyakarta: Pro U Media.

Thamrin, H. (2015). Enkulturisasi dalam Kebudayaan Melayu. Al-Fikra: Jurnal IImiah Keislaman, 14 (1), 98-147.

$\mathrm{Xu}$, N. (2017). The Association Between Parent-Child Relationship and Child Loneliness. Thesis. The Faculty of the Morgridge College of Education, University of Denver. 